\section{A novel missense RP1 mutation in retinitis pigmentosa}

\begin{abstract}
Aims More than 20 mutations associated with retinitis pigmentosa (RP) have been identified in the retinitis pigmentosa 1 (RP1) gene, all of them leading to the production of a truncated protein without $50-70 \%$ of the C-terminal of the RP1 protein. RP1 was recently found to be a microtubule-associated protein (MAP) and responsible for the organisation of the photoreceptor outer segment. The $\mathrm{N}$-terminal doublecortin (DCX) domain of RP1 is essential for its function. But how the C-terminal of the protein affects its function is still not known. This study aims to get a better understanding of the RP1 gene by mutation screening on RP patients. Methods Peripheral blood was taken from 72 RP patients. Together with 101 RP patients and 190 control subjects previously reported, mutation screening was performed by polymerase chain reaction (PCR) and direct sequencing. Statistical analysis was performed using SPSS.
\end{abstract}

Results Two novel missense sequence changes, D984G and C727W, and one novel

Department of Ophthalmology \& Visual Sciences, The Chinese University of Hong Kong, Hong Kong, China

Correspondence: CP Pang, Department of Ophthalmology \& Visual Sciences, The Chinese University of Hong Kong, Hong Kong Eye Hospital, 147K Argyle Street, Kowloon, Hong Kong Tel: + 852 27623169; Fax: + 85227159490 E-mail: cppang@ cuhk.edu.hk

Received: 15 December 2004

Accepted: 25 April 2005 Published online: 3 June 2005 variant, $6492 \mathrm{~T}>\mathrm{G}$, at the $3^{\prime}$ untranslated region were found. They were not found in $\mathbf{1 9 0}$ control subjects. D984G causes RP. It creates two possible $\mathrm{N}$-myristoylation sites according to PROSITE. C727W does not segregate with $\mathrm{RP}$ in the family. It abolishes an Nmyristoylation site. $\mathrm{R} 872 \mathrm{H}$, a previously reported polymorphism, was predominantly present in control subjects $(P=0.001)$. Conclusions Our results suggest that disruption of the C-terminal of RP1 may be associated with the development of RP, and the possible involvement of the RP1 polypeptide downstream of its DCX domain in normal RP1 function.

Eye (2006) 20, 602-605. doi:10.1038/sj.eye.6701944; published online 3 June 2005

Keywords: RP1; C-terminal; retinitis pigmentosa; myristoylation site
SWY Chiang, DY Wang, WM Chan, POS Tam, KKL Chong, DSC Lam and CP Pang

\section{Introduction}

Retinitis pigmentosa (RP) is a heterogeneous group of inherited diseases which cause the progressive degeneration of vision.

Abnormalities of the photoreceptors of the retina will lead to progressive visual loss and even complete blindness after middle age. ${ }^{1} \mathrm{RP}$ affects over 1.5 million people worldwide. The genetics of RP is complex. According to family history, RP can be classified as autosomal dominant (adRP), autosomal recessive (arRP), X-linked or sporadic. Among all RP patients, $40-50 \%$ are sporadic cases while adRP and arRP account for 15-25\% and $5-20 \%$, respectively. About 5-15\% of the RP patients are of X-linked RP. ${ }^{2}$ Retinitis pigmentosa 1 (RP1) is one of the genes associated with RP. ${ }^{3}$ It encodes a polypeptide chain of 2156 amino acids. To date, more than 20 RP1 mutations associated with RP have been identified, all leading to the production of truncated proteins without $50-70 \%$ of the carboxy chain..$^{4-11}$ The most commonly occurring mutation is $\mathrm{R} 677 \mathrm{X}$, present in 3\% of adRP patients in the US. ${ }^{4,6,7,8,9}$ In Chinese RP patients, R677X occurs at a lower frequency $(0.6 \%){ }^{11}$

It is known that all components in the outer segment of rod photoreceptor cells, including proteins for phototransduction, must be first synthesised in the inner segment and then transported to the outer segment. ${ }^{12}$ In RP1 knockout mice, there was progressive death of rod photoreceptors and a mislocalisation of rhodopsin in the inner segments and cell bodies of the photoreceptors. Such mislocalisation of rhodopsin suggested that the RP1 protein may play a role in the transport of rhodopsin across the cell membranes. ${ }^{5,13}$ Moreover, the presence of RP1 in the connecting cilia, which is thought to be a channel for protein transport between the inner and the outer segments, further proves the involvement of RP1 in protein transportation. ${ }^{5}$ 
Recently, RP1 was found to be the first photoreceptor microtubule-associated protein (MAP) identified based on the colocalisation and coassembly with microtubules, and also the effect on microtubule polymerisation. ${ }^{14}$ The MAP activities of RP1 are primarily mediated by the DCX domains. ${ }^{5,14}$ The N-terminal portion of RP1, of 233 amino acid residues, where the DCX domain is situated, stimulates microtubule formation and stabilises cytoplasmic microtubule in heterologous cells. Mutations of the RP1 gene in mice cause the misorientation of the outer segment discs. Therefore, RP1 is involved in outer segment organisation and the DCX domain of RP1 has a functional role..$^{5,14,15}$

However, the function and the importance of the protein region downstream of the DCX domain, where most mutations occurr (codons 658-1053), have not been demonstrated. Since the function and structure of the RP1 protein is still not clearly understood and most genetic studies on RP were conducted in Caucasian subjects, we screened additional Chinese RP patients to search for more naturally occurring mutations of the $R P 1$ gene that are disease causing.

\section{Materials and methods}

We recruited 72 unrelated Chinese RP patients from the Hong Kong Eye Hospital and the Prince of Wales Hospital. They were given a complete ophthalmoscopic examination and identified by fundus examination. They all have typical history and clinical features of RP. This study was conducted in accordance with the Declaration of Helsinki, as revised in 1989. Informed consents were given by all subjects participating in this study. DNA was extracted from the peripheral blood of the subjects. In all, 26 amplimers covering coding exon $2(627 \mathrm{bp})$, exon 3 (172 bp), and exon 4 (6165 bp) of RP1 studied previously ${ }^{11}$ were being investigated by polymerase chain reaction (PCR) and direct DNA sequencing to detect sequence alterations in all samples. Statistical analysis was performed using SPSS, version 11.5.

The sequence alterations detected in these 72 patients were screened by direct DNA sequencing after PCR among 101 RP patients and 190 unrelated Chinese control subjects who were recruited for our previous studies $^{11}$ from the Hong Kong Eye Hospital and the Prince of Wales Hospital. We therefore obtained frequencies of RP1 sequence variants in a total of 173 patients and 190 controls. All the control subjects had been given a full ophthalmoscopic examination to ensure they had not developed any eye diseases except mild senile cataracts. They were all aged above 60 years and had no systemic diseases or family history.

\section{Results}

We found 19 sequence alterations (Table 1), 16 of which have been previously reported. ${ }^{11}$ Two missense sequence changes, D984G and C727W (GenBank accession number

Table 1 Sequence alterations identified in RP1 in our study

\begin{tabular}{|c|c|c|c|c|}
\hline Codon change & Nucleotide change & Frequency in $R P$ patient & Frequency in controls & References \\
\hline $\mathrm{R} 249 \mathrm{H}$ & $746 \mathrm{G}>\mathrm{A}$ & $1 / 173$ & $0 / 190$ & Baum et $a l^{11}$ \\
\hline M479I & $1437 \mathrm{G}>\mathrm{T}$ & $1 / 173$ & $0 / 190$ & Baum et $a l^{11}$ \\
\hline R677X & $2029 \mathrm{C}>\mathrm{T}$ & $1 / 173$ & $0 / 190$ & Reported RP causative mutation ${ }^{\mathrm{a}}$, Pierce $e t a l^{3}$ \\
\hline G706R & $2116 \mathrm{G}>\mathrm{C}$ & $3 / 173$ & $1 / 190$ & Baum et $a l^{11}$ \\
\hline C727W & $2180 \mathrm{~T}>\mathrm{G}$ & $2 / 173$ & $0 / 190$ & Novel variant \\
\hline $\mathrm{R} 872 \mathrm{H}^{\mathrm{b}}$ & $2615 G>A$ & $66 / 173$ & $130 / 190$ & Sullivan et $a l^{7}$ \\
\hline D984G & $2951 \mathrm{~A}>\mathrm{G}$ & $1 / 173$ & $0 / 190$ & Novel RP causative mutation \\
\hline N985Y & $2953 \mathrm{~A}>\mathrm{T}$ & $20 / 173$ & $27 / 190$ & Sullivan et $a l^{7}$; Jacobson $e t a l^{8}$ \\
\hline Q1008Q & $3024 \mathrm{G}>\mathrm{A}$ & $1 / 173$ & $1 / 190$ & Baum et $a l^{11}$ \\
\hline Q1063R & $3188 \mathrm{G}>\mathrm{A}$ & $0 / 173$ & $1 / 190$ & Baum et $a l^{11}$ \\
\hline $\mathrm{A} 1670 \mathrm{~T}^{\mathrm{c}}$ & $5008 \mathrm{G}>\mathrm{A}$ & $82 / 173$ & $106 / 190$ & Sullivan $e t a l^{7}$; Jacobson $e t a l^{8}$ \\
\hline $\mathrm{S} 1691 \mathrm{P}^{\mathrm{c}}$ & $5071 \mathrm{~T}>\mathrm{C}$ & $82 / 173$ & $106 / 190$ & Sullivan et $a l^{7}$; Jacobson $e t a l^{8}$ \\
\hline $\mathrm{Q}^{1725 Q^{c}}$ & $5175 \mathrm{~A}>\mathrm{G}$ & $82 / 173$ & $106 / 190$ & Sullivan $e t a l^{7}$; Jacobson $e t a l^{8}$ \\
\hline R1933X & $5797 \mathrm{C}>\mathrm{T}$ & $0 / 173$ & $1 / 190$ & Baum et al ${ }^{11}$ \\
\hline$C 2033 Y^{d}$ & $6098 \mathrm{G}>\mathrm{A}$ & $18 / 173$ & $27 / 190$ & Sullivan $e t a l^{7}$; Jacobson $e t a l^{8}$ \\
\hline $\mathrm{I} 2141 \mathrm{M}$ & $6423 \mathrm{~A}>\mathrm{G}$ & $0 / 173$ & $1 / 190$ & Baum et al ${ }^{11}$ \\
\hline $3^{\prime} \mathrm{UTR}$ & $6492 \mathrm{~T}>\mathrm{G}$ & $1 / 173$ & $0 / 190$ & Novel \\
\hline $3^{\prime} \mathrm{UTR}$ & $6542 \mathrm{C}>\mathrm{T}$ & $1 / 173$ & $2 / 190$ & Baum et $a l^{11}$ \\
\hline $3^{\prime} \mathrm{UTR}$ & $6676 \mathrm{~T}>\mathrm{A}$ & $1 / 173$ & $2 / 190$ & Baum et al $l^{11}$ \\
\hline
\end{tabular}

${ }^{\text {aRP }}$ causative mutations refer to variants that change the amino-acid sequences of the encoded polypeptide and are found only in RP patients and not in normal controls. The mutation should be also segregated with RP in the family.

${ }^{\mathrm{b}}$ The difference of allele frequency was significant between RP patients and control subjects $(P<0.001)$.

${ }^{c}$ These three sequence alterations always occurred together. The difference of allele frequency between RP patients and control subjects is not significant. However, the genotype frequency is significantly higher in control subjects $(P=0.04)$.

${ }^{\mathrm{d}}$ The difference of allele frequency was significant between RP patients and control subjects $(P=0.03)$. 
AY672590), ${ }^{16}$ and one variant at the $3^{\prime}$ untranslated region, $6492 \mathrm{~T}>\mathrm{G}$, are novel sequence alterations found in RP patients in this study. They were absent in the 190 control subjects.

One RP patient was heterozygous for D984G. Her son also carries this sequence alteration. He was aged 19 years and did not have typical features of RP. But there were already signs of fundus abnormality and pigmentation. He was developing vision impairment. Therefore, he was very likely to develop RP later in life. We searched the RP1 polypeptide sequence on PROSITE $^{17}$ and found D984G affected the $\mathrm{N}$-myristoylation sites. Amino-acid residue 984 resides on a region that does not belong to any predicted protein families or domains. When the charged aspartic acid is replaced by the tiny nonpolar glycine, two possible N-myristoylation sites appear. One is in residue 980-985 (GLTGGN) and the other one is in residue 983-988 (GGNLCK).

One arRP patient and one adRP patient were heterozygous for $\mathrm{C} 727 \mathrm{~W}$ but their family members are negative for this sequence change despite some of them being RP patients. PROSITE search revealed that this polymorphism abolished one N-myristoylation site in the protein. Residue 723-728 in RP1 (GGILCE) has a high probability of being an N-myristoylation site. When the small, uncharged cysteine in residue 727 is replaced by the aromatic tryptophan, this putative $\mathrm{N}$-myristoylation site is abolished.

$6492 \mathrm{~T}>\mathrm{G}$ was found in one arRP patient. No family member of this patient was available for this study. $\mathrm{R} 872 \mathrm{H}$ was more predominant in controls $(68 \%)$ than in RP patients $(38 \%)(P=0.001)$. A1670T, S1691P and Q1725Q were found to always coexist.

\section{Discussion}

The RP1 protein is the first photoreceptor-specific MAP being identified. It is located in the connecting cilia and axoneme of the photoreceptor. The N-terminal 233 residue of the RP1 polypeptide (which contains the DCX domain) is important for the normal function of RP1. 5,13,14,18 Mutations in the RP1 gene that cause RP often lead to the production of a truncated protein. R677X is a recurrent mutation in Caucasian RP patients. Therefore, at least part of the polypeptide sequence from residue 677 onwards is responsible for the normal function of the RP1 protein. RP1 is composed of 2156 amino acids. Apart from the two DCX domains present in the N-terminal portion of RP1 protein (DCX 1 extends from residue 36-118 and DCX 2 extends from residue 154-233), many glycosylation, phosphorylation and $\mathrm{N}$-myristoylation sites are predicted to be present throughout the entire length of the polypeptide. $3,7,17,18$
N-myristoylation is an important lipid modification of a number of eukaryotic proteins. This modification refers to the transfer of myristiate from myristoyl-coenzyme A to the N-terminal glycine residue of the proteins through an amide linkage and under the catalytic activity of N-myristoyl-transferase (NMT) (Figure 1). It alters the hydrophobicity of the protein and thus influences the partitioning of the protein to cellular membranes. It is involved in directing and anchoring proteins to cell membranes, and is associated with cellular regulation, signal transduction, translocation and even apoptosis of the cell. ${ }^{19,20}$ The importance of $\mathrm{N}$-myristoylation is shown in recoverin, which is a calcium-binding protein found in retinal rod outer segment. Recoverin is capable of inhibiting rhodopsin phosphorylation by rhodopsin kinase. N-myristoylation of the recoverin is essential for the association of the protein with the photoreceptor membrane, which enhances its inhibitory effect. ${ }^{21}$ Owing to the limited information on the structural and functional relationship of $\mathrm{RP} 1$, the effect of $\mathrm{N}$-myristoylation on RP1 is unclear.

The two novel naturally occurring and missense RP1 variants identified in this study, D984G and C727W, are situated in the region where most sequence variations of RP1 are found (codons 658-1053). D984G causes RP but C727W does not. According to PROSITE, which predicts the occurrence of protein families and domains based on the similarities in protein sequences, ${ }^{17}$ D984G creates two $\mathrm{N}$-myristoylation sites and C727W abolishes one. Addition of two N-myristoylation sites in the region downstream of the DCX domain by D984G likely promotes interactions of the RP1 protein with other proteins or with cell membranes. Whether conformational changes are induced remains to be investigated. But either a putative new protein interaction or conformational change may disrupt the normal function of RP1. If an interacting protein is involved, such as RHO, it may lead to photoreceptor cell death and thus cause RP. On the other hand, disruption of one N-myristoylation site, by C727W, did not have disease consequence, indicating the RP1 function was not affected. Our results give indications for the first time that N-myristoylation sites downstream of the DCX

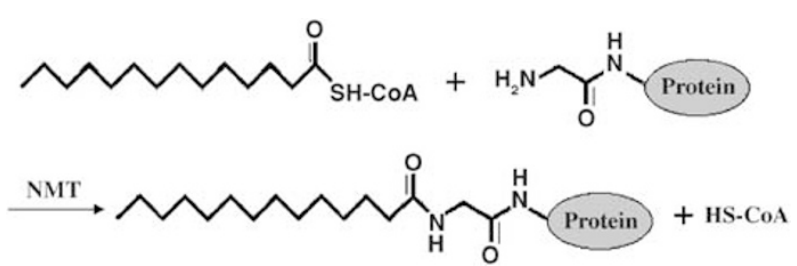

Figure 1 Schematic diagram showing the N-myristoylation reaction. 
domain of the RP1 polypeptide may affect RP1 function and attribute to RP. However, apart from the lack of information on the mechanism of the functional or structural disruption in RP1 caused by D984G, there is another concern in that PROSITE may not be a reliable program to predict $\mathrm{N}$-myristoylation. ${ }^{19,22,23}$ Therefore, further work to identify the precise disruption of RP1 structure and function is warranted to understand the underlying mechanism.

\section{References}

1 Kalloniatis M, Fletcher EL. Retinitis Pigmentosa: understanding the clinical presentation, mechanisms and treatment options. Clin Exp Optom 2004; 87(2): 65-80.

2 www.genetests.org

3 Pierce EA, Quinn T, Meechan T, McGee TL, Berson EL, Dryja TP. Mutations in a gene encoding a new oxygenregulated photoreceptor protein cause dominant retinitis pigmentosa. Nat Genet 1999; 22: 248-254.

4 Guilonneau X, Piriev NI, Danciger M, Kozak CA, Cideciyan AV, Jacobson SG et al. A nonsense mutation in a novel gene is associated with retinitis pigmentosa in a family linked to the RP1 locus. Hum Mol Genet 1999; 8: 1541-1546.

5 Liu Q, Zhou J, Daiger SP, Farber DB, Heckenlively JR, Smith JE et al. Identification and subcellular localization of the RP1 protein in human and mouse photoreceptor. Invest Ophthalmol Vis Sci 2002; 43: 22-23.

6 Bowne SJ, Daiger SP, Hims MM, Sohocki MM, Malone KA, McKie AB et al. Mutations in the RP1 gene causing autosomal dominant retinitis pigmentosa. Hum Mol Genet 1999; 8: 2121-2128.

7 Sullivan LS, Heckenlively JR, Bowne SJ, Zuo J, Hide WA, Gal A et al. Mutations in a novel retina-specific gene cause autosomal dominant retinitis pigmentosa. Nat Genet 1999; 22: 255-259.

8 Jacobson SG, Cideciyan AV, Iannaccone A, Weleber RG, Fishman GA, Maguire AM et al. Disease expression of RP1 mutations causing autosomal dominant retinitis pigmentosa. Invest Ophthalmol Vis Sci 2000; 41: 1898-1908.

9 Payne A, Vithana E, Khaliq S, Hameed A, Deller J, AbuSafieh L et al. RP1 protein truncating mutations predominate at the RP1 adRP locus. Invest Ophthalmol Vis Sci 2000; 41: 4069-4073.

10 Schwartz SB, Aleman TS, Cideciyan AV, Swaroop A, Jacobson SG, Stone EM. De novo mutation in the RP1 gene (Arg677ter) associated with retinitis pigmentosa. Invest Ophthalmol Vis Sci 2003; 44: 3593-3597.

11 Baum L, Chan WM, Yeung KY, Lam DS, Kwok AKH, Pang CP. RP1 in Chinese: eight novel variants and evidence that truncation of the extreme C-terminal does not cause retinitis pigmentosa. Hum Mut 2001; 17(5): 436.

12 Hollyfield JG, Besharse JC, Rayborn ME. Turnover of rod photoreceptor outer segment. I: membrane addition and loss in relationship to temperature. J Cell Biol 1977; 75: 490-506.

13 Gao J, Cheon K, Nusinowitz S, Liu Q, Bei E, Atkin K et al. Progressive photoreceptor degeneration, outer segment dysplasiam and rhodopsin mislocalization in mice with targeted disruption of the retinitis pigmentosa-1 (Rp1) gene. Proc Natl Acad Sci USA 2002; 99: 5698-5703.

14 Liu Q, Zuo J, Pierce EA. The retinitis pigmentosa 1 protein is a photoreceptor microtubule-associated protein. J Neurosci 2004; 24: 6427-6436.

15 Liu Q, Lyubarsky A, Skalet JH, Pugh Jr EN, Pierce EA. RP1 is required for the correct stacking of outer segment discs. Invest Ophthalmol Vis Sci 2003; 44: 4171-4178.

16 http://www.ncbi.nlm.nih.gov/Genbank

17 http://tw.expasy.org/prosite/

18 http://www.ncbi.nlm.nih.gov/

19 Maurer-Stroh S, Eisenhaber B, Eisenhaber F. N-terminal $\mathrm{N}$-myristoylation of proteins: refinement of the sequence motif and its taxon-specific differences. J Mol Biol 2002; 317: 523-540.

20 http://www.chemie.uni-karlsruhe.de/OC/biochem/ lutz.html

21 Senin II, Zargarov AA, Alekseev AM, Gorodovikova EN, Lipkin VM, Philippov PP. N-myristoylation of recoverin enhances its efficiency as an inhibitor of rhodopsin kinase. FEBS Lett 1995; 376: 87-90.

22 Boisson B, Giglione C, Meinnel T. Unexpected protein families including cell defense components feature in the Nmyristoylome of a higher eukaryote. J Biol Chem 2003; 278: 43418-43429.

23 Utsumi T, Nakano K, Funakoshi T, Kayano Y, Nakao S, Sakurai $\mathrm{N}$ et al. Vertical-scanning mutagenesis of amino acids in a model $\mathrm{N}$-myristoylation motif reveals the major amino-terminal sequence requirements for protein N-myristolation. Eur J Biochem 2004; 271: 863-874. 